九州大学学術情報リポジトリ

Kyushu University Institutional Repository

\title{
Modeling and Prioritizing Price - Based Demand Response Programs in The Wholesale Market in Japan
}

\section{Ma Lehmirchegini, Ladan}

Energy and Environmental Systems Laboratory, Interdisciplinary Graduate School of Engineering Sciences, Kyushu University

Farzaneh, Hooman

Energy and Environmental Systems Laboratory, Interdisciplinary Graduate School of Engineering Sciences, Kyushu University

https://doi.org/10.5109/4738592

出版情報: Proceedings of International Exchange and Innovation Conference on Engineering \& Sciences (IEICES). 7, pp. 224-231，2021-10-21. 九州大学大学院総合理工学府 バージョン:

権利関係 : 


\title{
Modeling and Prioritizing Price - Based Demand Response Programs in The Wholesale Market in Japan
}

\author{
Ladan Malehmirchegini $^{1 *}$, Hooman Farzaneh ${ }^{1}$ \\ ${ }^{1}$ Energy and Environmental Systems Laboratory, Interdisciplinary Graduate School of Engineering Sciences, Kyushu \\ University, Fukuoka, Japan \\ ${ }^{*}$ Corresponding author email: malehmirchegini.ladan.982@s.kyushu-u.ac.jp
}

\begin{abstract}
In the traditional electricity market, the safety of power systems due to increasing power demand, especially in peak -valley, is seriously affected. In recent years, the smart electricity market's development, and the implementation of demand response programs (DRPs) have resulted in electricity price reduction, improving loads with demand flexibility, and enhancing security by interacting between customers and the market. The main aim of this study is an optimization model of price-responsive demand in the wholesale market in Japan considering the concept of dynamic price elasticity of demand, single and multi-period loads, and customer benefit function. The proposed model is founded on the theories of price and customer in microeconomics which can help decision-makers in the electricity market evaluate the customers' behaviors based on the decision variables like the price of electricity and customers' participation level and incentives. The customer benefit function is derived based on the self and cross-price elasticities of demand and single and multi-period loads. Moreover, different Time-Based Programs (TBP) of DRPs are applied to the model to evaluate the effect of changing the price on customers' demand. DRPs are prioritized using Multi Criteria Decesion Matrix (MCDM) technique in orderto help decision makers for prioritizing different DRPs to improve load profile features. The developed model is tested in the next step, using day-ahead spot price from the Japan Electric Power Exchange (JEPX) and demand loads in Wholesale Market in Japan.
\end{abstract}

Keyword: Demand respnse programs, smart grid, customer behavior, elasticity matrix

\section{INTRODUCTION}

Information and communication technologies are conducting current cities towards smart cities, which leads to becoming more effective, comfortable, and sustainable and allowing them to reach more considerable energy savings. Some essential parts of smart cities like green and smart buildings, intelligent transportation systems, autonomous cars, smart grid, water security, and resilience can be considered different kinds of sustainable social infrastructures. As a major consumer and importer of energy with 0.93 trillion $\mathrm{kWh}$ used annually, Japan can be considered the fifth-largest electricity-consuming country globally. Measures to increase energy efficiency to achieve projected demand in 2030 with the energy mix are being implemented [1]. Among all countermeasures recommended by the Japanese government, Demand Response (DR) is a voluntary program that allows end-user customers to reduce their electricity usage during periods of higher power prices and also to achieve specific outcomes on the electrical grid at varying levels. Research demonstrating the importance of mathematical modeling and formulation of the demand-responsive mechanism in the electricity market has gained more attention from scholars worldwide. The main aim of the study is to find the optimal electricity consumption behavior of customers in response to conditions in the wholesale market. To this aim, in this study, an optimization model of price-responsive demand in the wholesale market in Japan is introduced, considering the concept of dynamic price elasticity of demand, single and multi-period loads, and customer benefit function.

The rest of this paper is prepared as follows. Section 2 describes the demand response programs and different types of them. In section3, the customer benefit function is derived based on the self and cross-price elasticities of demand and single and multi-period loads, and the price elasticity matrix (PEM) will be addressed and the values of dynamic price elasticity of electricity demand will be estimated, respectively. . In section4, some techniques of Multi-Criteria Decision Matrix (MCDM) are presented to prioritized DRPs utilized in this paper. Section 5 presents the numerical results of different Time-Based Programs (TBP) of DRPs applied to the model to estimate the effect of fluctuating the price on customers' consumption. Finally, Section 6 presents the conclusion.

\section{DEMAND RESPONSE PROGRAMS}

DRPs, which play an increasingly important role in energy markets, can be considered an effective effort to reduce energy demand by changing energy consumption due to changes in tariffs or incentive rates [2]. These programs that network, market, and customers can benefit from them in the short term are designed to increase the power reliability and prevent price spikes. One of the noticeable difficulties for a DR program is balancing energy and save costs for both the customers and the utility sectors. It is because the customers want to minimize their energy cost, while the utility tries to manage existing energy considering cost minimization [3].

In this paper, we address different TBPs and apply them to the model to evaluate the effect of changing the price on customer demand. Based on the Federal Energy Regulatory Commission, TBP is divided into three types, as shown in Fig.1 [3].

\subsection{Time of use (TOU)}

Under a TOU pricing scheme, the prices of electricity depend on different pricing intervals. For instance, a day can be divided into three intervals including peak, midpeak, and off-peak intervals that it is ordinary tried to shift the shiftable loads to the off-peak interval. 


\subsection{Critical peak pricing (CPP)}

Except for the time in which the power reliability is endangered, this program has similarities with TOU.

\subsection{Real-time pricing (RTP)}

In this plan, the electricity tariffs are changed and announced on a day ahead or hour-ahead basis, before the start of each period.

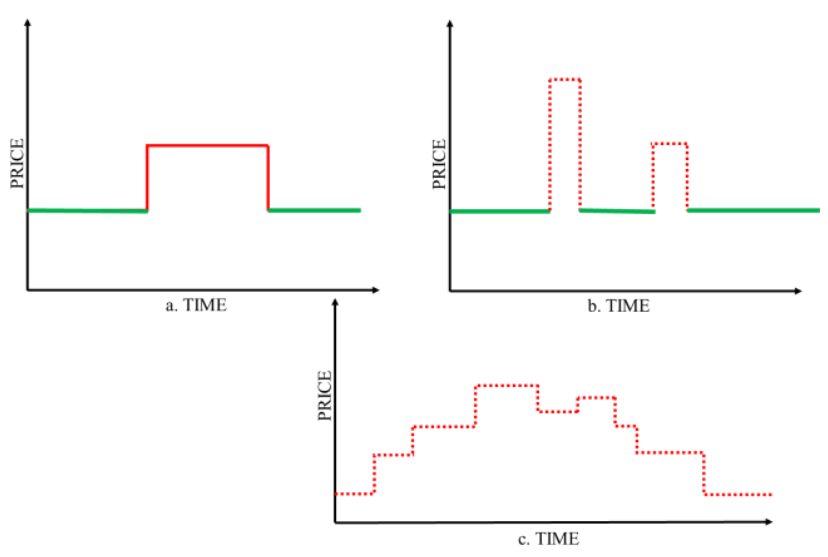

Fig. 1: Time-varying price schemes (a) Time-of-Use (ToU), (b) Critical-Peak Pricing, and (c) Real-TimePricing

\section{MODEL DEVELOPMENT}

Maintaining the profits of the utility sector and the customer and balancing the benefits of both of them are the most critical factors for DRPs. It is essential to identify the behavioral characteristics of the customers to realize their willingness to participate in DRPs considering their profit optimized. By identifying the customer's willingness to participate in DR programs, savings in electricity costs can be projected with a reduction in electricity usage during peak periods. Schweppe et al. developed a system considering the spot pricing of electricity in which users would change their consumption depending on the spot price of electricity [4]. Several studies have addressed the demandresponsive mechanism in the electricity market to estimate the customers' behavior considering the priceelasticity concept [5],[6].

In this paper, the benefit function is modeled as a function of the customer's utility and cost of the electricity to investigate the behavior of the customer with the contribution in the DRPs [7]. The customer benefit function as an economic load model is developed based on subtracting the electricity cost from the customer utility function to specify changes in the customer's demand considering the contribution in the price-based DR programs [8].

Customer's benefit maximization is formulated as follows:

$B\left(d_{i}\right)=U\left(d_{i}\right)-d_{i} \cdot \pi_{i}$

(7)
Where, the first term refers to the utility function and the second term is the cost of electricity consumption. $\pi$ refers to the price of electricity.

Since individual customer benefit is a nonlinear function, the quadratic form of customer benefit most often used doing a first-order Taylor Series expansion is applied in this study as follow:

$U\left(d_{i}\right)=U_{0, i}+\pi_{0, i}\left[d_{i}-d_{0, i}\right]\left\{1+\frac{d_{i}-d_{0, i}}{2 \varepsilon_{i, i} \cdot d_{0, i}}\right\}$

The combination of the single period loads, which can be shifted from peak period to off-peak or can be switched either on or off in the multi-period loads, is expressed as follows [9]:

$d_{i}=d_{0, i}\left\{1+\frac{\varepsilon_{i, i}\left[\pi_{i}-\pi_{0, i}\right]}{\pi_{0, i}}+\sum_{\substack{j=1 \\ i \neq j}}^{24} \frac{\varepsilon_{i, j}\left[\pi_{j}-\pi_{0, j}\right]}{\pi_{0, j}}\right\}$

(9)

\section{$i=1,2, \ldots, 24$}

According to the above equation, the customer demand changes from $d_{0, i}$ (the initial demand) to $d_{i}$ after participation in the DR program can be calculated. $\varepsilon_{i, i}$ and $\varepsilon_{i, j}$ are the self and cross elasticities of demand, respectively.

A price elasticity matrix ( PEM) is a matrix consist of price-to-electric-use elasticities on $a$ 24-hour interval can be expressed as [10]:

$E=\left[\begin{array}{cccc}\varepsilon_{1,1} & \varepsilon_{1, j} & \cdots & \varepsilon_{1,24} \\ \varepsilon_{2,1} & \varepsilon_{i, i} & \cdots & \varepsilon_{i, 24} \\ \vdots & \vdots & \cdots & \vdots \\ \varepsilon_{24,1} & \varepsilon_{24, j} & \cdots & \varepsilon_{24,24}\end{array}\right]$

(4)

Therefore, the electricity demand variations during a day can be expressed as[11]:

$\left[\begin{array}{c}\frac{\Delta Q_{1}}{Q_{1}} \\ \frac{\Delta Q_{2}}{Q_{2}} \\ \vdots \\ \frac{\Delta Q_{24}}{Q_{24}}\end{array}\right]=\mathrm{E} \times\left[\begin{array}{c}\frac{\Delta P_{1}}{P_{1}} \\ \frac{\Delta P_{2}}{P_{2}} \\ \vdots \\ \frac{\Delta P_{24}}{24}\end{array}\right]$

Mostly, elasticity can be estimated through statistical estimation, using historical data. According to the econometric analysis, the elasticity can be estimated in a specified range by linear regression, by applying a loglinear form or double-log functional model.

In this research, the price elasticity of demand in the Japan day-ahead market was estimated, considering the relationship between price and demand values at each half-hour of the day and show that demand is changing to price movements in the short run. In this model, electricity demand is a linear function of electricity price and two other variables that reflect the impact of climatic conditions on electricity consumption. These two independent variables are introduced as heating degree days (HDD) and cooling degree days (CDD), which probably have a positive effect on electricity usage [12] :

$\Delta Q_{i}=\alpha+\beta \Delta P_{i}+\gamma \mathrm{HDD}+\rho \mathrm{CDD}$

where $\Delta$ denotes the first difference operator and $\mathrm{i}=1,2$, $\ldots, \mathrm{T}$, represents the time interval. $\Delta Q_{i}$ is electricity consumption in hour i. $\beta, \gamma, \rho$ are coefficients of the independent variables, respectively. In order to estimate the coefficient of the aforementioned linear regression 
model, Panel data analysis based on the fixed effects technique was applied to the data sets of the spot prices of electricity and demand loads which were obtained from the Japan Electric Power Exchange (JEPX) [13],[14]. The estimated values for the dynamic price elasticity of electricity demand $(\beta)$ on 24 -hour interval is given in Table 1.

\section{PROCEDURE OF PRIORITIZING DRP}

Regulators in the electricity market always try to find the best programs of DR to implement, considering different main viewpoints in the market based on the generator, service provider, and customers' preferences. To this aim, Multi-Criteria Decision Making (MCDM) methods are conducted to help regulators prioritize different DRPs to improve load profile features. In this paper, first, the Entropy Ranking Technique (ERT) is considered as a weighting technique to evaluate different criteria in the MCDM model. Then, after finding the weight of each criterion, the Order of Preference by Similarity to Ideal Solution (TOPSIS) analysis is applied to prioritize the implementation of programs. A brief explanation of conducting MCDM model in this paper will be discussed as follows[15]:

In the first part, the entropy technique, some economic and technical attributes to namely customer bill, peak reduction, electrical energy consumption reduction, load factor, and peak to valley distance for each program, are considered for making a decision matrix for implementing the entropy technique, table.2. In this matrix, columns show different criteria and rows represent alternatives and $C_{j i}$ refers to the performance of $\mathrm{jth}$ alternative for ith criterion.

$D=\left[\begin{array}{cccc}C_{11} & \ldots \ldots \ldots \ldots & C_{1 n} \\ \ldots & \ldots \ldots \ldots . . & \ldots \\ C_{j m 1} & \ldots \ldots \ldots \ldots & C_{m n}\end{array}\right]$

after making the decision matrix, all elements should be normalized as follows:

$C N_{i j} \frac{c_{i j}}{\sum_{i=1}^{m} c_{i j}}$

Then, the entropy of every normalized criterion, deviation degree is calculated with the following equations, 12,13 respectively:

Entropy $=-K \sum_{i=1}^{m}\left[C N_{i} \times L_{n} C N_{i}\right] \quad 0 \leq$ Entropy $\leq$ 1

(12)

$\mathrm{K}$ is defined as a positive constant.

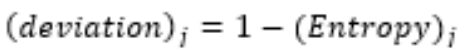

(13)

Finally, the weight and improved weight of each attribute can be estimated by bellow equations:

(weighting $)_{j}=\frac{(\text { deviation })_{j}}{\sum_{j=1}^{n}(\text { deviation })_{j}}$

(improved weighting $)_{j}=\frac{\lambda_{j} \times(\text { weighting })_{j}}{\sum_{j=1}^{n} \lambda_{j} \times(\text { weighting })_{j}}$
Which $\lambda_{j}$ is the importance factor of each attribute.

In the second part, the TOPSIS method is applied for calculating the distance between each alternative and the ideal and anti-ideal points. The procedure of this method is started with making a decision matrix and normalized all elements of it based on the following equation, step 1:

$r_{i j}=\frac{C_{i j}}{\sqrt{\sum_{i=1}^{m} C_{i j}^{2}}}$

After normalizing the decision matrix, it is needed to find the weight of all normalized elements with equation 17 , step 2:

$W_{i j}=(\text { weighting })_{i} \times r_{i j}$

Then, the ideal and anti-ideal solutions will be estimated for each attribute based on each column's minimum and maximum values, considering each attribute's preferences and different viewpoints. It means that, for instance, the highest and lowest values of energy consumption can be considered as maximum and minimum vectors of ideal and anti ideal solutions considering customer viewpoints, in that these values can be considered vise versa regarding service provider viewpoints, step 3 .

Ideal $=\left\{W 1^{+}, W 2^{+}, \ldots, W 1^{n+}\right\}$

Anti-Ideal $\quad=\quad\left\{W 1^{-}, W 2^{-}, \ldots, W 1^{n-}\right\}$ (18)

After selecting the ideal and anti ideal solutions, it is needed to calculate the distance between each alternative to the ideal anti-ideal solution. Finally for sorting the alternatives, the mean distance from the anti-ideal solution. The equations 19,20 and 21 are used for the calculation of this part, step 4.

$\begin{array}{cc}\left.D^{+}{ }_{i}=\sqrt{\sum_{j=1}^{n}(} W_{i j}-W^{+}{ }_{j}\right)^{2} & , \mathrm{i}=1, \ldots, \mathrm{m} \\ \left.D^{-}{ }_{i}=\sqrt{\sum_{j=1}^{n}(} W_{i j}-W^{-}{ }_{j}\right)^{2} & , \mathrm{i}=1, \ldots, \mathrm{m} \\ \text { mean distance }=\frac{D^{-}{ }_{i}}{D^{+}{ }_{i}+D^{-}} \quad, \mathrm{i}=1, \ldots, \mathrm{m}\end{array}$

The largest value of the mean distance is considered the best program.

The prices of each program and the elasticities can be seen in Table1. Calculations for all steps are presented in tables 2 and 4. The result of prioritizing the DRPs can be seen in Fig.2, it can be obtained that implementing CPP is the first priority, after that, TOU and RTP are the next steps.

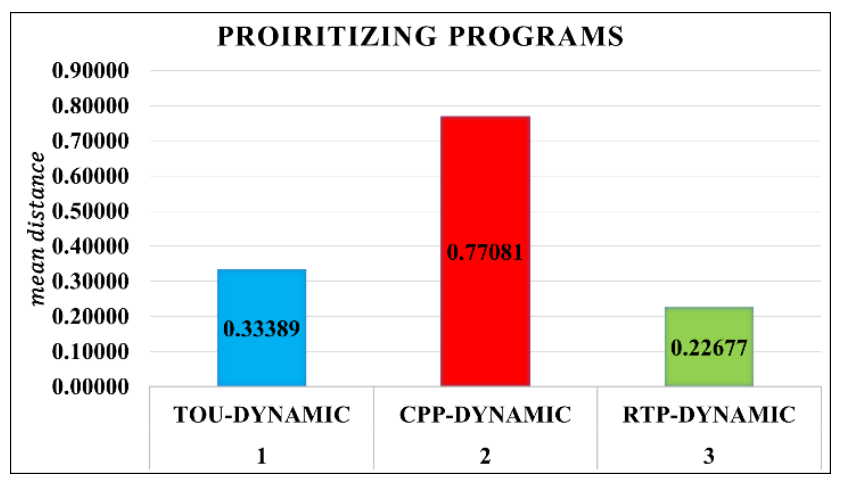

Fig. 2: the result of prioritizing programs 


\section{RESULTS AND DISCUSSION}

In this section, the actual peak load curve of the Japanese power grid (annual peak load) has been used for our estimation. We selected three days in each season with the highest, lowest, and medium ambient temperature and calculate the cumulative energy saving from the implementation of TOU, CPP, and RTP programs on those days considering dynamic elasticities. Then we found a range for the energy saving in each season. As shown in Fig.3, the TOU was applied to the three-time intervals, including peak, off-peak, and valley period, taking into account three different tariffs for each interval, based on the pattern range of tariffs determined in the Tokyo Electric Power Company TEPCO.

The loads in the 11th and 20th hours are considered critical peak, so the price of electricity during those periods usually is about three times more than flat rate prices when applying for the CPP program using realtime energy costs in peak intervals and a combination of TOU and flat-rate pricing programs [8].

Since electricity price is calculated based on hourly energy cost, more different tariffs are applied to the model to run the RTP program.

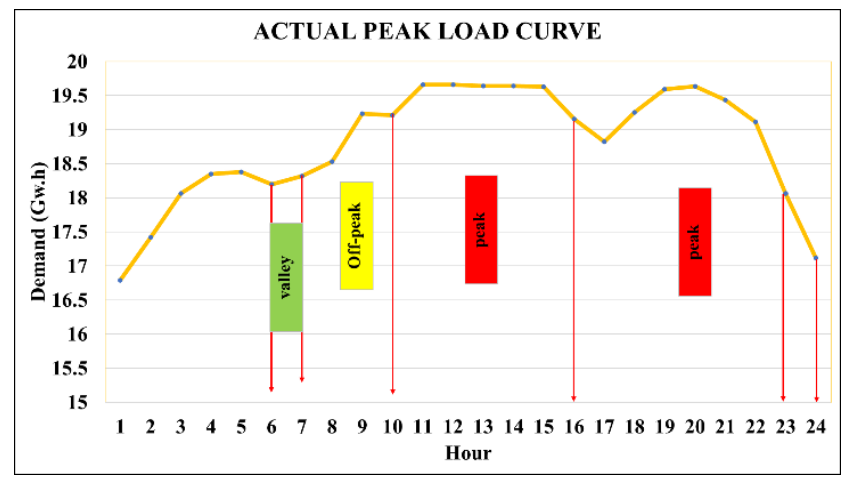

Fig. 3: actual peak load curve of Tokyo in a day

The results of the different DR programs for $1^{\text {st }}$ April, 2020, considering dynamic elasticities, are shown in Figures 4 to 7 show the result of the implementation of TOU in the data of June 17,2020 , as a hot day in the hot season.

By deploying DRPs on three days in each season with the greatest, lowest, and medium ambient temperatures, a range for energy savings was determined. The amount of energy-saving fluctuates between $4 \%$ and $2 \%$ depending on the season, as shown in Table 5.

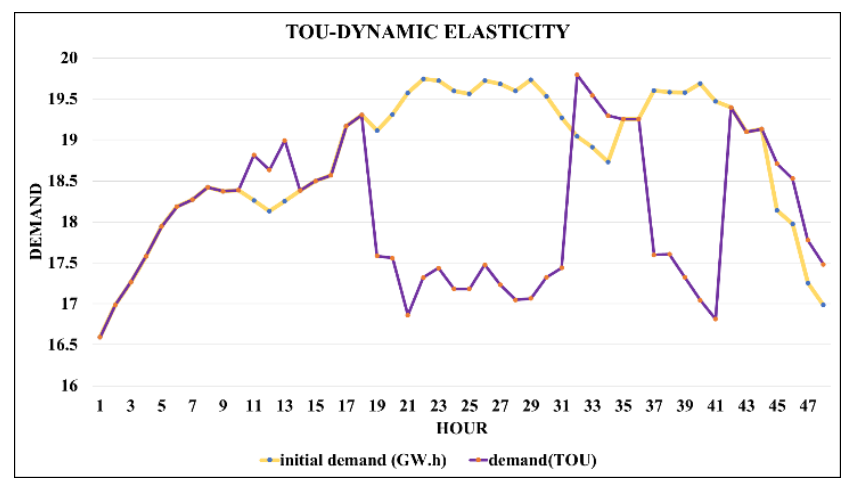

Fig. 4: Demand changes for the TOU on $1^{\text {st }}$ April, 2020

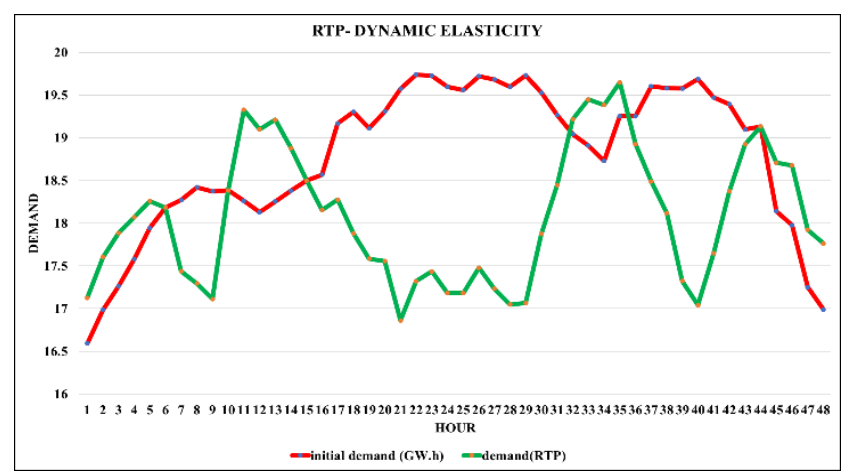

Fig. 5: Demand changes for the RTP on $1^{\text {st }}$ April, 2020 
Table 1. Initial loads and prices in DRPs

\begin{tabular}{|c|c|c|c|c|c|c|}
\hline hour & $\begin{array}{c}\text { Load } \\
d_{0, \mathrm{i}}[\mathrm{GWh}]\end{array}$ & $\begin{array}{c}\text { Initial } \\
\text { Price } \\
\pi(\text { 円 } \\
/ \mathbf{k W h})\end{array}$ & $\begin{array}{c}\text { TOU } \\
\pi(\text { 円/kWh)- }\end{array}$ & $\begin{array}{c}\text { CPP } \\
\pi(\text { 円/kWh })\end{array}$ & $\begin{array}{c}\text { RTP } \\
\pi(\text { 円/kWh })\end{array}$ & $\begin{array}{c}\text { Dynamic } \\
\text { elasticity }(\beta)\end{array}$ \\
\hline 1 & 16.8 & 6.69 & 6.69 & 6.69 & 3.5 & -0.07195 \\
\hline 2 & 17.4 & 6.56 & 6.56 & 6.56 & 4 & -0.08173 \\
\hline 3 & 18.1 & 6.505 & 6.505 & 6.505 & 5.75 & -0.07729 \\
\hline 4 & 18.3 & 6.5 & 6.5 & 6.5 & 10.5 & -0.08644 \\
\hline 5 & 18.4 & 6.505 & 6.505 & 6.505 & 8.255 & -0.12596 \\
\hline 6 & 18.2 & 6.615 & 5 & 6.615 & 3.5 & -0.11879 \\
\hline 7 & 18.3 & 8.41 & 6.705 & 8.41 & 5 & -0.09728 \\
\hline 8 & 18.5 & 8.65 & 8.65 & 8.65 & 9.825 & -0.08297 \\
\hline 9 & 19.2 & 9.085 & 9.085 & 9.085 & 15.5 & -0.08508 \\
\hline 10 & 19.2 & 10.555 & 20.5 & 10.555 & 20.5 & -0.09064 \\
\hline 11 & 19.7 & 9.24 & 23.5 & 22.12 & 23.5 & -0.08491 \\
\hline 12 & 19.7 & 9.09 & 24.5 & 9.09 & 24.5 & -0.07059 \\
\hline 13 & 19.6 & 8.84 & 24.5 & 8.84 & 24.5 & -0.06648 \\
\hline 14 & 19.6 & 8.96 & 23.5 & 8.96 & 23.5 & -0.07857 \\
\hline 15 & 19.6 & 9.02 & 21.5 & 9.02 & 20 & -0.08948 \\
\hline 16 & 19.2 & 10.305 & 12.5 & 10.305 & 12 & -0.07441 \\
\hline 17 & 18.8 & 11.58 & 5 & 11.58 & 5 & -0.05616 \\
\hline 18 & 19.3 & 9.29 & 9.29 & 9.29 & 9 & -0.05812 \\
\hline 19 & 19.6 & 9.405 & 25 & 9.405 & 19.5 & -0.06131 \\
\hline 20 & 19.6 & 9.165 & 25 & 22.145 & 25 & -0.07209 \\
\hline 21 & 19.4 & 9.005 & 17 & 9.005 & 17.5 & -0.07797 \\
\hline 22 & 19.1 & 8.85 & 8.85 & 8.85 & 9.375 & -0.0791 \\
\hline 23 & 18.1 & 8.71 & 5 & 8.71 & 4.5 & -0.07269 \\
\hline 24 & 17.1 & 8.56 & 5 & 8.56 & 3.5 & -0.0715 \\
\hline
\end{tabular}

Table 2 . The decision matrix

\begin{tabular}{|c|c|c|c|c|c|}
\hline $\begin{array}{l}\text { Programs } \\
\text { No. }\end{array}$ & Alternatives & $\begin{array}{c}\text { Peak } \\
\text { Reduction } \\
\text { (GW.h) }\end{array}$ & $\begin{array}{c}\text { Energy } \\
\text { Consumption(GWh) }\end{array}$ & $\begin{array}{l}\text { Load factor } \\
(\%)\end{array}$ & $\begin{array}{l}\text { Peak to } \\
\text { valley } \\
(\mathrm{GWh})\end{array}$ \\
\hline 1 & "TOU-DYNAMIC & 7.785 & 918.69 & $87.0 \%$ & 0.05 \\
\hline 2 & CPP-DYNAMIC & 10.71 & 915.76 & $86.4 \%$ & 0.06 \\
\hline 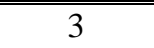 & "RTP-DYNAMIC & 6.82 & 919.85 & $86.7 \%$ & 0.05 \\
\hline 4 & $\begin{array}{l}\text { Improved } \\
\text { Weighting factor } \\
\text { from the entropy } \\
\text { technoque }\end{array}$ & 0.29 & 0.0068 & 0.005 & 0.112 \\
\hline
\end{tabular}

Table 3 . normalized decision matrix for the TOPSIS method

\begin{tabular}{||l||c||c||c||c||c||}
\hline \hline $\begin{array}{l}\text { Programs } \\
\text { No. }\end{array}$ & Alternatives & $\begin{array}{c}\text { Peak reduction } \\
(\mathrm{MWh})\end{array}$ & $\begin{array}{c}\text { Energy consumption } \\
(\mathrm{MWh})\end{array}$ & $\begin{array}{c}\text { Load factor } \\
(\%)\end{array}$ & $\begin{array}{c}\text { Peak to valley } \\
(\mathrm{GWh})\end{array}$ \\
\hline \hline 1 & $\begin{array}{c}\text { TOU- } \\
\text { DYNAMIC }\end{array}$ & 0.522 & 0.577 & 57.9 & 0.516 \\
\hline \hline 2 & $\begin{array}{c}\text { CPP- } \\
\text { DYNAMIC }\end{array}$ & 0.719 & 0.575 & 57.5 & 0.681 \\
\hline \hline 3 & $\begin{array}{c}\text { RTP- } \\
\text { DYNAMIC }\end{array}$ & 0.458 & 0.578 & 57.7 & 0.520 \\
\hline
\end{tabular}


Table 4:the distance between each alternative to the ideal anti-ideal solution

\begin{tabular}{|l|l||c||c||c||}
\hline $\begin{array}{l}\text { Programs } \\
\text { No. }\end{array}$ & Alternatives & $D^{+}{ }_{i}$ & $D^{-}{ }_{i}$ & mean distance \\
\hline \hline 1 & TOU- & 0.0570 & 0.0285 & 0.3338 \\
\hline \hline 2 & DYNAMIC & & 0.0756 & 0.7708 \\
\hline \hline
\end{tabular}

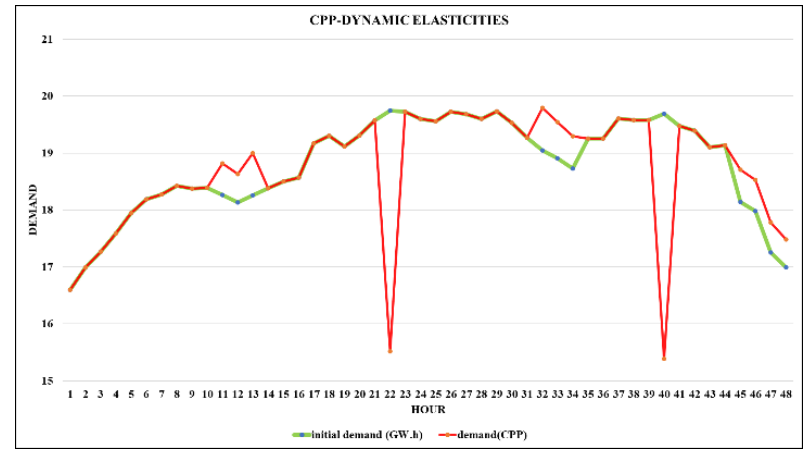

Fig. 6: Demand changes for the CPP on $1^{\text {st }}$ April, 2020

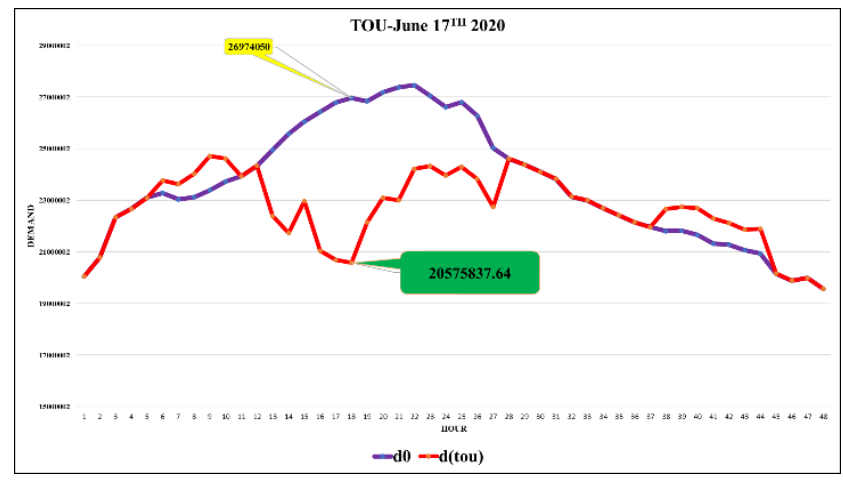

Fig. 7: Demand changes for the TOU program on June 172020

The numerical results of evaluating main economic and technical criteria, namely customer bill, peak reduction, electrical energy consumption reduction, load factor, and peak to valley distance for each program before and after implementing DRPs considering dynamic elasticity for the day of October 2020 is given in Figures 8 to 11. Based on the findings, it can be shown that by implementing each DR program, the load factor improves, and the distance between the peak and the valley decreases. The largest electricity bill was found to be associated with the state in which the CPP program was implemented, as the price of electricity grew dramatically under this program, but electricity use did not drop in proportion to the increase in power costs. Also, the lowest customer profit is obtained in this program. This indicates that the time span over the peak period and the degree of pricing differentiation between peak and off-peak times are essential elements in the CPP program. After CPP, the majority of peak reduction is attributed to running the TOU program, which aims to reduce load during the relatively few, costly hours more dynamically. The best value of peak to the valley and load factor are achieved in the TOU program. The outcomes of the TOU program in different seasons in Tokyo are represented in Table 5.

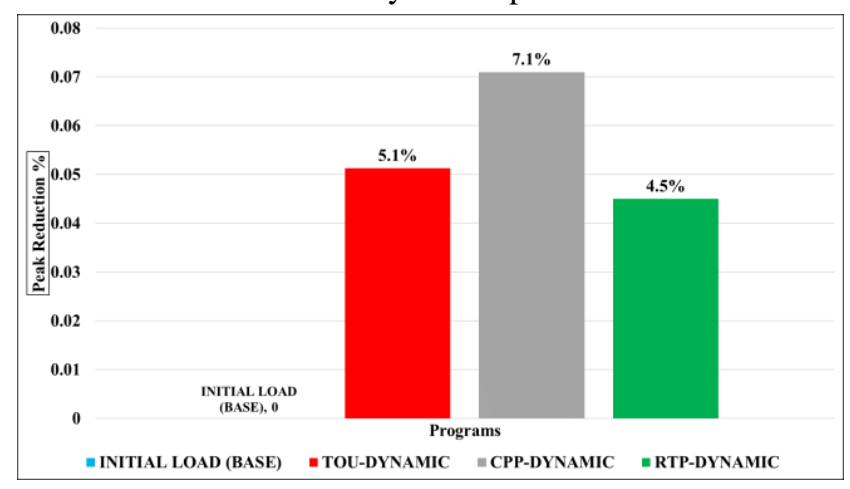

Fig. 8: Priority of the DRPs programs (peak reduction)

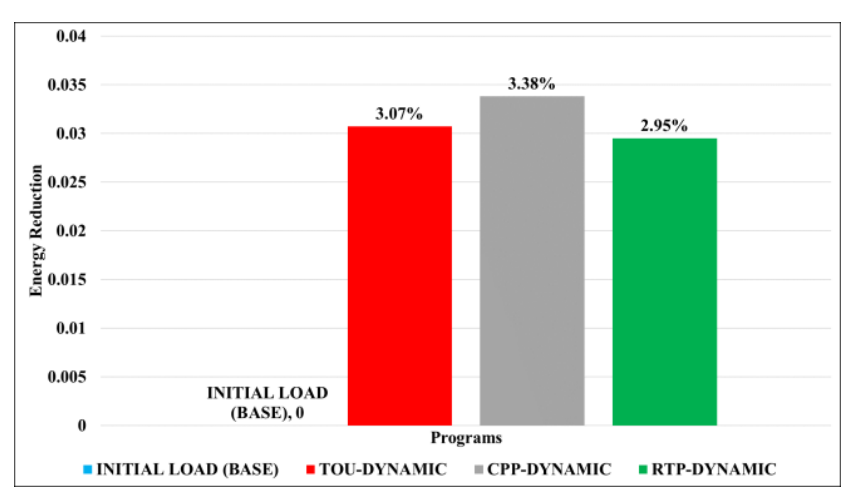

Fig. 9: Priority of the DRPs programs (energy saving)

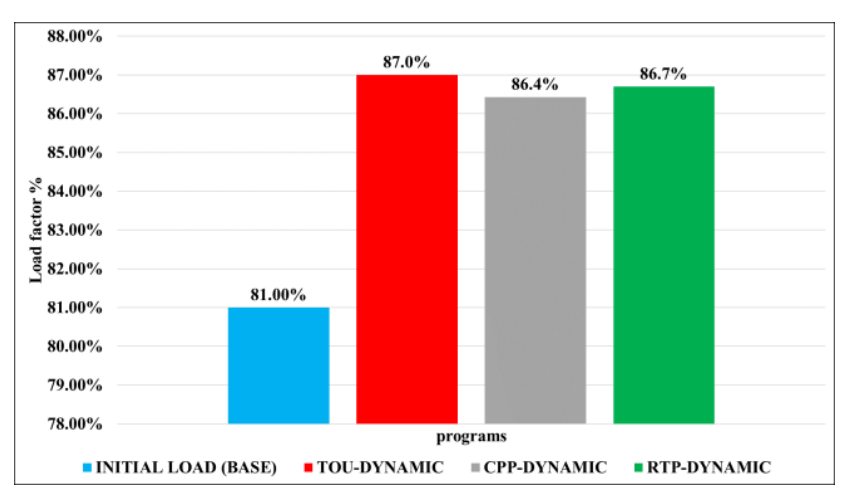

Fig. 10: Priority of the DRPs programs (load factor) 


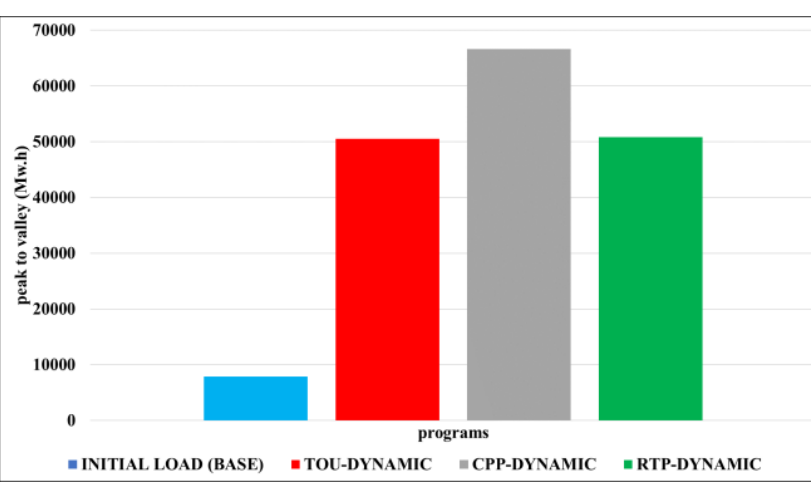

Fig. 11: Priority of the DRPs programs (peak to valley)

\section{CONCLUSION}

In this study, a demand response model was developed, considering the dynamic price elasticity of demand to estimate the energy saving of the different DRPs. The model findings indicate that by adopting DPRs in Tokyo, particularly the TOU programs, the amount of energy saving ranges between $4 \%$ and $2 \%$ from hot to the cold season. By using the proposed model, decision-makers in the electricity market evaluate the customers' behaviors based on the decision variables like the price of electricity and customers' participation level. There are several assessments for assessing the performance of each program before and after the implementation of DRPs, taking into account the service provider and consumer perspectives.

It should be emphasized that we may prioritize the programs and select the most effective ones based on the numerous viewpoints in the electrical market, including independent system operators, service providers, and customers. In this study, based on the customer viewpoint, we conducted the MCDM technique to prioritize DRPs implemented here, and showed the result of prioritizing. Also, based on considering some economic and technical criteria mentioned before, for the given load curve and considering dynamic elasticities in different programs, running the TOU program is more effective and efficient in improving the load factor. Furthermore, implementing the CPP program is more effective than others when peak reduction and peak to valley distance are taken into account.

Table 5: Result of applying TOU in 4 seasons in Tokyo

\begin{tabular}{|c|c|c|c|}
\hline \multicolumn{4}{|c|}{ Winter } \\
\hline & December & January & February \\
\hline $\begin{array}{l}\text { Electricity Saving } \\
(\mathrm{GWh})\end{array}$ & 31.88 & 7.39 & 35.51 \\
\hline Percentage of saving energy & $3 \%$ & $1 \%$ & $3 \%$ \\
\hline Average of saving & \multicolumn{3}{|c|}{$2.33 \%$} \\
\hline \multicolumn{4}{|c|}{ Spring } \\
\hline & March & April & May \\
\hline $\begin{array}{l}\text { Electricity Saving } \\
(\mathrm{GWh})\end{array}$ & 35.09 & 35.09 & 43.99 \\
\hline
\end{tabular}

\begin{tabular}{||l|c|c|c||}
\hline Percentage of saving energy & $4 \%$ & $4 \%$ & $4 \%$ \\
\hline Average of saving & \multicolumn{2}{|c||}{$4 \%$} \\
\hline & June & July & August \\
\hline & 45.77 & 57.44 & 39.12 \\
\hline $\begin{array}{l}\text { Electricity Saving } \\
\text { (GWh) }\end{array}$ & $4 \%$ & $5 \%$ & $3 \%$ \\
\hline $\begin{array}{l}\text { Percentage of saving energy } \\
\text { Average of saving }\end{array}$ & Fall & $4 \%$ & \\
\hline \multicolumn{2}{|c|}{ September } & October & Novembr \\
\hline & 39.51 & $29 . .211$ & 45.33 \\
\hline $\begin{array}{l}\text { Electricity Saving } \\
(\text { GWh })\end{array}$ & $4 \%$ & $3 \%$ & $4 \%$ \\
\hline \begin{tabular}{l} 
Percentage of saving energy \\
\hline Average of saving
\end{tabular} & \multicolumn{2}{|c||}{$3.6 \%$} \\
\hline
\end{tabular}

\section{REFERENCES}

[1] "Renewables," 2020, [Online]. Available: https://www.iea.org/reports/renewables-2020.

[2] R. Batchu and N. M. Pindoriya, Wireless and Satellite Systems, vol. 154. 2015.

[3] Federal Energy Regulatory Commission, "0907-Demand-Response.Pdf (Application/Pdf Objeto)," 2007, [Online]. Available: http://www.ferc.gov/legal/staff-reports/09-07demand-response.pdf.

[4] D. S. Kirschen, G. Strbac, P. Cumperayot, and D. P. De Mendes, "Factoring the elasticity of demand in electricity prices," IEEE Trans. Power Syst., vol. 15, no. 2, pp. 612-617, 2000, doi: $10.1109 / 59.867149$.

[5] A. Niromandfam, A. S. Yazdankhah, and R. Kazemzadeh, "Modeling demand response based on utility function considering wind profit maximization in the day-ahead market," $J$. Clean. Prod., vol. 251, p. 119317, 2020, doi: 10.1016/j.jclepro.2019.119317.

[6] F. Divina, M. G. Torres, F. A. G. Vela, and J. L. V. Noguera, "A comparative study of time series forecasting methods for short term electric energy consumption prediction in smart buildings," Energies, vol. 12, no. 10, 2019, doi: 10.3390/en12101934.

[7] F. C. Schweppe, M. C. Caramanis, R. D. Tabors, and R. E. Bohn, Spot Pricing of Electricity the Kluwer International Series. 1988.

[8] H. Aalami, G. R. Yousefi, and M. Parsa Moghadam, "A MADM-based support system for DR programs," Proc. Univ. Power Eng. Conf., no. June, 2008, doi: 10.1109/UPEC.2008.4651455.

[9] M. P. Moghaddam, A. Abdollahi, and M. Rashidinejad, "Flexible demand response programs modeling in competitive electricity markets," Appl. Energy, vol. 88, no. 9, pp. 3257- 
3269, 2011, doi: 10.1016/j.apenergy.2011.02.039.

[10] J. Wang, "by," 2009.

[11] K. Men, J. Wu, and S. Zhou, "Regulation power evaluation method of demand response by electricity price-demand elasticity matrix considering equipment fault rate," Proc. 2019 IEEE 2nd Int. Conf. Autom. Electron. Electr. Eng. AUTEEE 2019, pp. 66-70, 2019, doi: 10.1109/AUTEEE48671.2019.9033403.

[12] S. Okajima and H. Okajima, "Estimation of Japanese price elasticities of residential electricity demand, 1990-2007," Energy Econ., vol. 40, pp. 433-440, 2013, doi: 10.1016/j.eneco.2013.07.026.

[13]

“4aa82c9bdfd0b8610f1a9b45951a2e6e1bf3793 $8 @$ @www.jepx.org." [Online]. Available: http://www.jepx.org/english/.

[14] O. Torres-reyna, "Panel Data Analysis Fixed and Random Effects longitudinal or cross- is a dataset in which the behavior of entities are observed across time .," Princet. Univ., vol. Data and S, no. December, 2007.

[15] H. A. Aalami, M. P. Moghaddam, and G. R. Yousefi, "Modeling and prioritizing demand response programs in power markets," Electr. Power Syst. Res., vol. 80, no. 4, pp. 426-435, 2010, doi: 10.1016/j.epsr.2009.10.007. 